\title{
Arbekacin treatment of a patient infected with a Pseudomonas putida producing a metallo-beta-lactamase
}

Yoshiaki Iwashita*, Tomoyuki Enokiya, Kei Suzuki, Kazuto Yokoyama, Akitaka Yamamoto, Ken Ishikura, Masahiro Okuda and Hiroshi Imai

\begin{abstract}
Treatment of infections caused by multidrug-resistant Pseudomonas species is difficult because few antibiotics active against such organisms are available. Arbekacin, a relatively new aminoglycoside, is effective against Pseudomonas spp. in vitro. However, no clinical report on arbekacin treatment of a human infection with a multidrug-resistant Pseudomonas has appeared to date. We encountered a case of pneumonia caused by a Pseudomonas strain producing a metallo-beta-lactamase; the patient was successfully treated with arbekacin. A 69-year-old male presented to our hospital experiencing cardiac arrest after rescue from water. Spontaneous circulation had earlier resumed after brief application of cardiopulmonary resuscitation. The patient was subjected to induced hypothermia. He experienced severe acute respiratory distress syndrome. The patient regained consciousness on day 8 post-admission. Episodes of ventilator-associated pneumonia were recorded on days 5 and 12. The causative organism was a strain of Pseudomonas putida that produced a metallo-beta-lactamase. Combination therapy with arbekacin and levofloxacin successfully resolved the pneumonia. The patient was transferred to another hospital on day 37 to undergo further rehabilitation. Strains of P. putida producing metallo-beta-lactamases have become more widespread in recent years. Colistin is traditionally the drug of last resort to treat infections with multidrug-resistant Pseudomonas. However, colistin use is associated with a very high frequency of adverse effects, and the costs of such therapy are not covered by the Japanese health insurance system. Our results indicate that arbekacin is an efficient alternative to multidrug-resistant Pseudomonas.
\end{abstract}

Keywords: Metallo-beta-lactamase, Pseudomonas putida, Arbekacin

\section{Background}

Infections caused by Pseudomonas putida strains that produce metallo-beta-lactamases (MBLs) are difficult to treat because effective antibiotics are lacking. Colistin, the traditional drug of last resort, is not available in Japan, and the choice of antibiotic treatment for P. putida infections is thus limited. Combination therapy including arbekacin (ABK), an aminoglycoside antibiotic, has been reported to be effective against multidrug-resistant Pseudomonas aeruginosa in vitro [1]. To the best of our knowledge, no clinical report on ABK treatment of pneumonia caused by MBL-producing $P$. putida has yet appeared. We present a case featuring successful treatment,

\footnotetext{
*Correspondence: iwaci1ta@clin.medic.mie-u.ac.jp

Emergency and Critical Care Center, Mie University Hospital, Edobashi 2-174, Tsu, Mie 514-8507, Japan
}

\section{P. putida.}

\section{Case presentation}

A 69-year-old male presented to our hospital post cardiac arrest. The patient had been in a fishing boat that had accidentally overturned. The patient was rescued by others nearby, who called an ambulance. When the paramedics arrived on scene, his Glasgow Coma Scale was 1-1-1, and his $\mathrm{SpO}_{2}$ is $76 \%(10 \mathrm{~L} / \mathrm{min}$ reservoir mask). Cardiac arrest occurred in the ambulance. Spontaneous circulation returned after 2 min of CPR. He was intubated on scene and was transferred to our hospital by helicopter.

On arrival at our hospital, his vital signs were BP 122/60 mmHg, $\mathrm{HR} 71$ beats/min, and $\mathrm{SpO}_{2} 93 \%$ (SIMV $\mathrm{FiO}_{2}$ 1.0, PEEP $10 \mathrm{cmH}_{2} \mathrm{O}$, peak inspiratory pressure 25 


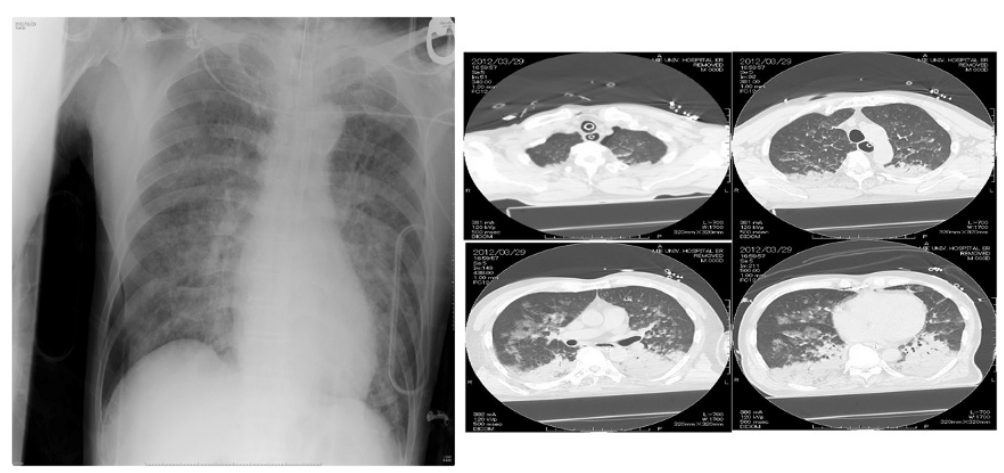

Figure 1 Chest X-ray and CT scan upon ICU admission. Chest radiograph shows diffuse infiltrate bilaterally.

$\mathrm{cmH}_{2} \mathrm{O}$, and pressure support $10 \mathrm{cmH}_{2} \mathrm{O}$ ). The Glasgow Coma Scale score was 1-T-5, and the diameter of his pupils was $4 \mathrm{~mm} \times 4 \mathrm{~mm}$ with light reflex of $+/+$. Respiratory sounds were evident as coarse crackles bilaterally. A chest X-ray showed diffuse bilateral infiltration (Figure 1). A chest CT scan revealed infiltrates bilaterally in the dependent lung regions and left multiple costal fractures with pneumohemothorax, probably attributable to chest compression. Arterial blood gas revealed the presence of mixed acidosis with severe hypoxia: $\mathrm{pH}$ 7.04, $\mathrm{PaO}_{2} 52 \mathrm{mmHg}, \mathrm{PaCO}_{2} 52 \mathrm{mmHg}, \mathrm{HCO}_{3} 14.1$ $\mathrm{mmol} / \mathrm{L}, \mathrm{BE}-16.6 \mathrm{mmol} / \mathrm{L}$, and lactate $5.4 \mathrm{mmol} / \mathrm{L}$. The white blood cell count was slightly elevated to

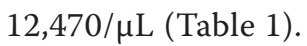

The patient was diagnosed as post cardiac arrest due to severe hypoxia. He was subjected to induced hypothermia $\left(34^{\circ} \mathrm{C}\right.$ for $\left.24 \mathrm{~h}\right)$. A chest drainage tube was inserted to treat the left-side pneumohemothorax. The ventilator setting was changed to the airway pressure-releasing ventilation mode; the relevant settings were $P_{\text {high }} 26 \mathrm{cmH}_{2} \mathrm{O}, P_{\text {low }} 5$ $\mathrm{cmH}_{2} \mathrm{O}, T_{\text {high }} 3.5 \mathrm{~s}, T_{\text {low }} 0.5 \mathrm{~s}$, and $\mathrm{FiO}_{2}$ 0.6. The ARDS was treated via nitric oxide inhalation $(10 \mathrm{ppm})$, and the patient was placed in prone position. Sulbactam-ampicillin $(1.5 \mathrm{~g}$ every $6 \mathrm{~h})$ treatment was commenced for prophylaxis of aspiration pneumonia. The clinical course is shown in Figure 2. The patient was rewarmed on day 6 , at which time he had fully recovered neurologically.

On day 4, the patient developed late-onset ventilatorassociated pneumonia. We initiated empirical therapy with tazobactam-piperacillin $4.5 \mathrm{~g}$ every $8 \mathrm{~h}$ and vancomycin hydrochloride $1 \mathrm{~g}$ every $12 \mathrm{~h}$. The patient experienced general edema and impairment of renal function, and the blood concentration of vancomycin hydrochloride was thus much greater than the predicted value. We, therefore, replaced this drug with linezolid on day 7 . Culture of sputum taken on day 7 revealed the presence of methicillinsensitive Staphylococcus aureus. We changed linezolid to cefazolin on day 11 . Although the inflammatory symptoms improved slightly, fever and sputum production became worse on day 12 , and we suspected that a second episode of ventilator-associated pneumonia had developed. The patient required tracheostomy on day 13. On day 15, sputum culture taken on day 12 revealed the presence of a P. putida strain that produced an MBL (to be of the integron-encoded type revealed on day 38). The method of $P$. putida isolation was semi-quantitative, and the method of MBL detection was PCR method. Of the antibiotics

Table 1 Laboratory data on arrival

\begin{tabular}{|c|c|c|}
\hline & Number & Unit \\
\hline WBC & 12,470 & $/ \mu \mathrm{L}$ \\
\hline $\mathrm{Hb}$ & 12.6 & $\mathrm{~g} / \mathrm{dL}$ \\
\hline Platelet & 231,000 & $/ \mu \mathrm{L}$ \\
\hline Total protein & 6.9 & $\mathrm{~g} / \mathrm{dL}$ \\
\hline Albumin & 4.0 & $\mathrm{~g} / \mathrm{dL}$ \\
\hline Total bilirubin & 0.5 & $\mathrm{mg} / \mathrm{dL}$ \\
\hline AST & 74 & $\mathrm{IU} / \mathrm{L}$ \\
\hline ALT & 47 & IU/L \\
\hline LDH & 450 & IU/L \\
\hline ALP & 259 & IU/L \\
\hline CRP & 0.1 & $\mathrm{mg} / \mathrm{dL}$ \\
\hline CK & 679 & $\mathrm{IU} / \mathrm{L}$ \\
\hline BUN & 26 & $\mathrm{mg} / \mathrm{dL}$ \\
\hline Creatinine & 1.25 & $\mathrm{mg} / \mathrm{dL}$ \\
\hline $\mathrm{Na}$ & 146 & $\mathrm{mmol} / \mathrm{L}$ \\
\hline K & 3.4 & $\mathrm{mmol} / \mathrm{L}$ \\
\hline $\mathrm{Cl}$ & 113 & $\mathrm{mmol} / \mathrm{L}$ \\
\hline PT-INR & 0.82 & \\
\hline APTT & 16.2 & $\mathrm{sec}$ \\
\hline $\mathrm{pH}$ & 7.04 & \\
\hline PCO2 & 52.0 & $\mathrm{mmHg}$ \\
\hline $\mathrm{PO} 2$ & 85.0 & $\mathrm{mmHg}$ \\
\hline $\mathrm{HCO} 3$ & 14.1 & $\mathrm{mmol} / \mathrm{L}$ \\
\hline BE & -16.6 & $\mathrm{mmol} / \mathrm{L}$ \\
\hline Lactate & 5.4 & $\mathrm{mmol} / \mathrm{L}$ \\
\hline
\end{tabular}

Metabolic acidosis with lactate elevation was seen. 


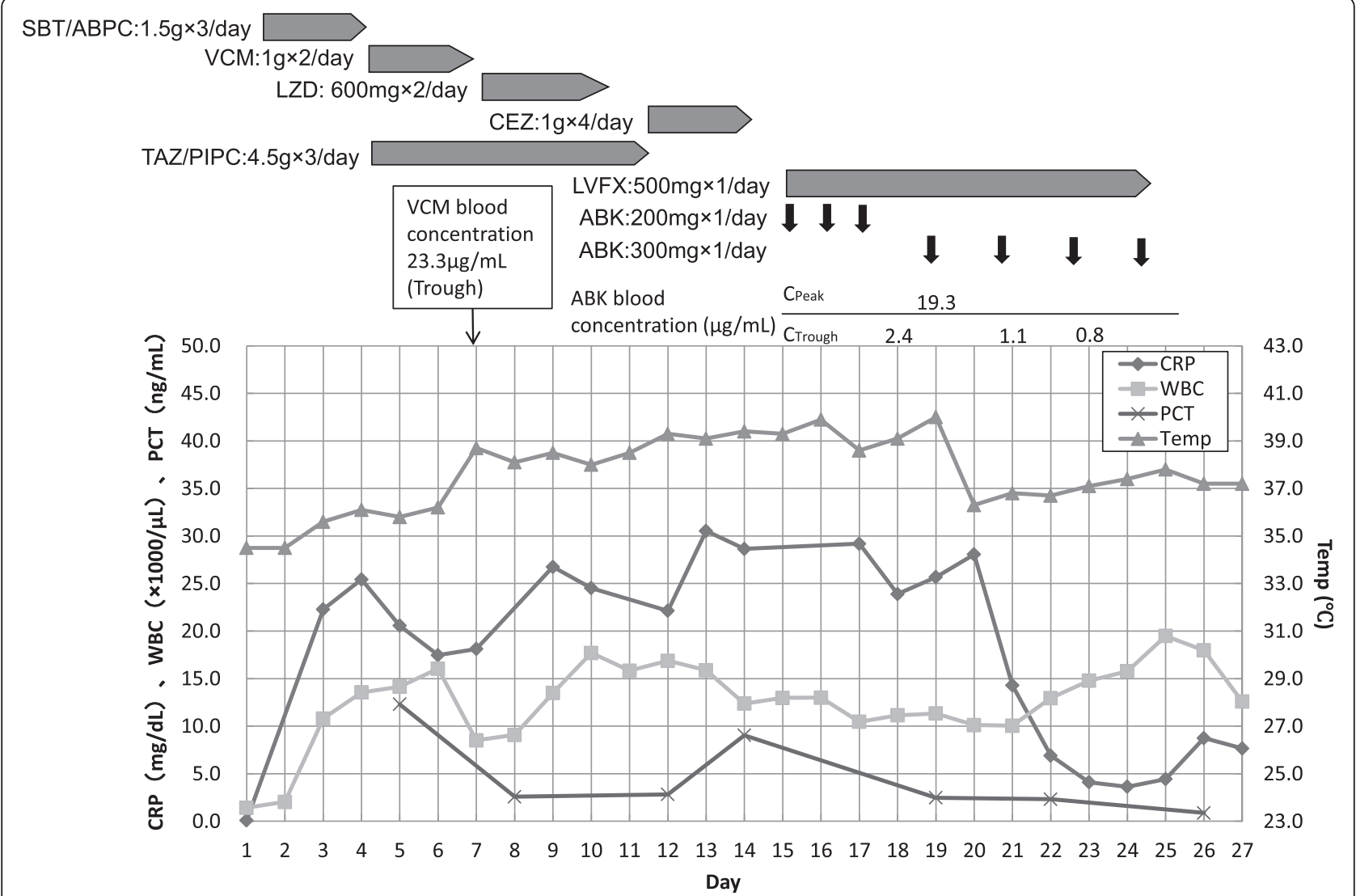

Figure 2 Clinical course of the patient. Inflammatory markers, dose, and duration of the antibiotics used are shown.

tested, the bacterium was sensitive only to amikacin (AMK), arbekacin, and minocycline. The minimum inhibitory concentration of ABK was $2.0 \mu \mathrm{g} / \mathrm{mL}$. The blood concentrations of AMK could not be measured in our hospital, whereas that of ABK can. We, therefore, chose to employ this drug in treatment. As reported above, the blood concentration of vancomycin exceeded the predicted value when the drug was used in the earlier treatment. We, therefore, resolved to carefully titrate ABK levels in the blood. Our final choice of therapy was ABK $300 \mathrm{mg}$ every $24 \mathrm{~h}$ with levofloxacin (LVFX) $500 \mathrm{mg}$ every $24 \mathrm{~h}$. We titrated $\mathrm{ABK}$ doses to maintain $C_{\text {peak }}$ values over $16 \mu \mathrm{g} / \mathrm{mL}$ and $C_{\text {trough }}$ values less than $2.0 \mu \mathrm{g} / \mathrm{mL}$. Inflammatory symptoms had decreased in extent by day 17 , but treatment with both drugs was continued up to day 26. The patient was transferred to another hospital on day 37 for further rehabilitation.

\section{Discussion}

The increasing prevalence of drug-resistant microbes is a major issue in modern critical care. Infections caused by MBL-producing $P$. putida are difficult to treat, especially in Japan, where health insurance covers the use of relatively few antibiotics. Here, we report on a case of pneumonia caused by MBL-producing P. putida; the patient was successfully treated with ABK.

P. putida is a fluorescent member of the Pseudomonas family and causes nosocomial infections, including pneumonia, urinary tract infections, neonatal infections, and adult bacteremia $[2,3]$. Pneumonia caused by $P$. putida is suspected to be associated with high mortality rates when bacteremia develops [3,4]. Our patient had experienced cardiac arrest and was subsequently subjected to induced hypothermia to prevent hypoxic brain injury. Our patient was, thus, susceptible to opportunistic nosocomial infections, especially of the lung.

Historically, P. putida has been considered to be an opportunistic pathogen of low virulence and has been susceptible to a range of antibiotics [5]. However, in both Japan and Korea, the isolation frequencies of imipenem-resistant Pseudomonas spp. (especially $P$. aeruginosa and $P$. putida) are increasing [6]. Most imipenem-resistant $P$. aeruginosa strains produce MBLs. In Korea, 8 of 12 (67\%) imipenemresistant P. putida isolated in 2005 expressed MBLs [6]. The MBL element of $P$. putida can be horizontally transferred to P. aeruginosa [7]. To date, eight types of MBLs 
have been identified and are known by the acronyms IMP, VIM, SPM, SIM, GIM, DIM, AIM, and KHM [8]. The IMP type was identified in the strain that infected our patient; this is the most common form of MBL in Japan. MBL detection was done by PCR method [9].

Colistin is the antibiotic of choice for treating infections with MBL-producing Pseudomonas spp. [10]. However, colistin therapy is not supported by Japanese health insurance. Arbekacin is a broad-spectrum aminoglycoside antibiotic, effective in treating infections with a range of bacteria, from Gram-positive cocci to Gram-negative bacilli. This antibiotic is indicated for treatment of infections with methicillin-resistant $S$. aureus and has been reported to effectively kill Pseudomonas spp. in vitro. However, the clinical effectiveness of ABK is not well known. Use of aminoglycoside antibiotics is associated with development of renal toxicity; the blood levels of such drugs must be therapeutically monitored. We initially prescribed VCM for our patient but found that the blood concentration thereof was much higher than what was expected and threatened to compromise renal function. We, thus, resolved to carefully monitor aminoglycoside levels in the blood of our patient. Of the drugs to which the isolate was sensitive, we chose to prescribe the aminoglycoside $A B K$ rather than AMK because it was possible to measure $\mathrm{ABK}$ blood concentrations (but not those of AMK) in our institution. ABK is a relatively new drug, and the pharmacokinetics and pharmacodynamics thereof remain not to be fully investigated. The optimal blood concentration of ABK has not yet been established. For aminoglycoside drugs, the ratio of peak blood concentration $\left(C_{\text {peak }}\right)$ to the minimal inhibitory concentration has been reported to be related to the clinical efficacy. Thus, a $C_{\text {peak }} / \mathrm{MIC}$ value greater than 8 was associated with a clinical efficacy of over $90 \%$ [11]. We therefore maintained the $C_{\text {peak }}$ level of ABK over $16 \mu \mathrm{g} / \mathrm{mL}$

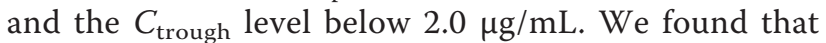
we could successfully maintain the desired drug blood concentrations by varying the drug dose.

We choose to additionally prescribe LVFX for two reasons. First, our patient had not earlier received any quinolone. Second, P. putida that are resistant to fluoroquinolones express a drug efflux system [12,13]. We therefore considered that LVFX might nonetheless be effective if given at high concentrations. However, later laboratory analysis revealed that the combination of ABK and LVFX was no more effective against the isolate in vitro than was ABK alone. Therefore, the observed clinical effect may have been attributable to the action of ABK alone.

The clinical course of our patient was favorable; no adverse events were noted. Thus, we propose that combination therapy that includes ABK may effectively treat infections with MBL-producing Pseudomonas spp.

\section{Conclusion}

We experienced a case of MBL-producing P. putida successfully treated with $\mathrm{ABK}$. $\mathrm{ABK}$ is an effective choice of treatment for MBL-producing Pseudomonas spp.

\section{Consent}

Written informed consent was obtained from the patient for publication of this case report and any accompanying images. A copy of the written consent is available for review by the Editor-in-Chief of this journal.

\section{Competing interest}

The authors declare that they have no competing interests.

\section{Authors' contributions}

TE carried out the drug resistant assays, genetic analysis of the bacteria, and contributed to draft the figures. YI, KS, KY, and AY contributed in drafting the manuscript. $\mathrm{KI}$ helped in resuscitating the patient and in drafting the manuscript. MO carried out the genetic analysis of the bacteria and helped in drafting the figures. HI participated in designing and drafting the manuscript. All authors read and approved the final manuscript.

\section{Acknowledgements}

We would like to thank Asami Masui, Eiji Kawamoto, Akihiro Shindo, Yukinari Omori, Tsuyoshi Hatada, Masaki Fujioka, and Taichi Takeda at the Emergency and Critical Care Center, Mie University Hospital, Japan for their contributions to this article.

Received: 4 June 2013 Accepted: 13 September 2013

Published: 23 October 2013

\section{References}

1. Araoka H, Baba M, Tateda K, Ishii Y, Oguri T, Okuzumi K, Oishi T, Mori S, Mitsuda T, Moriya K, Nakamori Y, Ohmagari N, Yamaguchi K, Yoneyama A, ABX Combination Therapy Study Group: In vitro combination effects of aztreonam and aminoglycoside against multidrug-resistant Pseudomonas aeruginosa in Japan. Jpn J Infect Dis 2012, 65:84-87.

2. Yoshio $Y$, Kitazawa $T$, Kamimura M, Tatsuno $K$, Ota $Y$, Yotsuyanagi $\mathrm{H}$ : Pseudomonas putida bacteremia in adult patients: five case reports and a review of the literature. J Infect Chemother 2011, 17:278-282.

3. Fujita J, Negayama K, Ohara M, Hojo S, Obayashi Y, Miyawaki H, Yamaji Y, Takahara J: Pneumonia caused by Pseudomonas putida with a mucoid phenotype. Resp Med 1998, 92:693-695.

4. Kim SE, Park SH, Park HB, Park KH, Kim SH, Jung SI, Shin JH, Jang HC, Kang SJ: Nosocomial Pseudomonas putida bacteremia: high rates of carbapenem resistance and mortality. Chonnam Med J 2012, 48:91-95.

5. Fass RJ, Barnishan J, Solomon MC, Ayers L: In vitro activities of quinolones, beta-lactams, tobramaycin, and trimethoprim-sulfamethoxazole against nonfermentative gram-negative bacilli. Antimicrob Agents Chemother 1996, 40:1412-1418.

6. Lee K, Park A, Kim MY, Lee HJ, Cho JH, Kang JO, Yong D, Chong Y, KONSAR group: Metallo-beta-lactamase producing Pseudomonas spp. in Korea: high prevalence of isolates with VIM-2type and emergence of isolates with IMP-1 type. Yonsei Med J 2009, 50:335-339.

7. Juan C, Zamorano L, Mena A, Alberti S, Perez JL, Oliver A: Metallo- $\beta$-lactamaseproducing Pseudomonas putida as a reservoir of multidrug resistance elements that can be transferred to successful Pseudomonas aeruginosa clones. J Antimicrob Chemother 2010, 65:474-478.

8. Queenan AM, Bush K: Carbapenemases: the versatile beta-lactamases. Clin Microbiol Rev 2007, 20:440-458.

9. Dallenne C, Da Costa A, Decre D, Favier C, Arlet G: Development of a set of multiplex PCR assays for the detection of genes encoding important $B$ lactamases in Enterobacteriaceae. J Antimicrob Chemother 2010, 65:490-495. 
10. Sabuda DM, Laupland K, Pitout J, Dalton B, Rabin H, Louie T, Conly J: Utilization of colistin for treatment of multidrug-resistant Pseudomonas aeruginosa. Can J Infect Dis Med Microbiol 2008, 19:413-418.

11. Moore RD, Lietman PS, Smith CR: Clinical response to aminoglycoside therapy: importance of peak concentration to minimal inhibitory concentration. J Infect Dis 1987, 155:93-99.

12. Horii T, Muramatsu $H$, linuma $Y$ : Mechanisms of resistance to fluoroquinolones and carbapenems in Pseudomonas putida. J Antimicrob Chemother 2005, 56:643-647.

13. Kieboom J, de Bont J: Identification and molecular characterization of an efflux system involved in Pseudomonas putida S12 multidrug resistance. Microbiology 2001, 147:43-51.

doi:10.1186/2052-0492-1-3

Cite this article as: Iwashita et al: Arbekacin treatment of a patient

infected with a Pseudomonas putida producing a metallo-beta-lactamase. Journal of Intensive Care 2013 1:3.

\section{Submit your next manuscript to BioMed Central and take full advantage of:}

- Convenient online submission

- Thorough peer review

- No space constraints or color figure charges

- Immediate publication on acceptance

- Inclusion in PubMed, CAS, Scopus and Google Scholar

- Research which is freely available for redistribution 